\title{
Short communication: Investigation into Mycobacterium avium ssp. paratuberculosis in pasteurized milk in Italy
}

\author{
A. Serraino, ${ }^{*}$ P. Bonilauri,† F. Giacometti, ${ }^{* 1}$ M. Ricchi,‡ G. Cammi,ł S. Piva, ${ }^{*}$ V. Zambrini,§ A. Canever,§ \\ and N. Arrigonif \\ *Department of Veterinary Medical Sciences, University of Bologna, Via Tolara di Sopra 50, 40064 Ozzano Emilia (BO), Italy \\ †Institute for Zooprophylaxis in Lombardy and Emilia-Romagna, Via Pitagora 2, 42100 Reggio Emilia, Italy \\ ‡National Reference Centre for Paratuberculosis, Experimental Institute for Zooprophylaxis in Lombardy and Emilia-Romagna, \\ Strada della Faggiola 1, 29027 Gariga di Podenzano (PC), Italy \\ §Granarolo s.p.a, Via Cadriano 27/2, 40121 Bologna, Italy
}

\section{ABSTRACT}

This study investigated the presence of viable $\mathrm{Myco-}$ bacterium avium ssp. paratuberculosis (MAP) in pasteurized milk produced by Italian industrial dairy plants to verify the prediction of a previously performed risk assessment. The study analyzed 160 one-liter bottles of pasteurized milk from 2 dairy plants located in 2 different regions. Traditional cultural protocols were applied to $500 \mathrm{~mL}$ of pasteurized milk for each sample. The investigation focused also on the pasteurization parameters and data on the microbiological characteristics of raw milk (total bacterial count) and pasteurized milk (Enterobacteriaceae and Listeria monocytogenes). No sample was positive for MAP, the pasteurization parameters complied with European Union legislation, and the microbiological analysis of raw and pasteurized milk showed good microbiological quality. The results show that a $7-\log ($ or $>7$ ) reduction could be a plausible value for commercial pasteurization. The combination of hygiene practices at farm level and commercial pasteurization yield very low or absent levels of MAP contamination in pasteurized milk, suggesting that pasteurized milk is not a significant source of human exposure to MAP in the dairies investigated.

Key words: Mycobacterium avium ssp. paratuberculosis, pasteurized milk

\section{Short Communication}

Mycobacterium avium ssp. paratuberculosis (MAP) is the causative agent of paratuberculosis, also called Johne's disease, primarily affecting the small intestine of ruminants. Mycobacterium avium ssp. paratuberculosis was considered to carry a zoonotic risk, on the basis of both clinical and gross lesion similarities between

Received June 16, 2016.

Accepted September 11, 2016.

${ }^{1}$ Corresponding author: federica.giacometti3@unibo.it
Johne's disease and human Crohn's disease and PCR evidence of MAP in the gut of Crohn's disease patients (Chiodini et al., 2012). Recent reports show that humans, like other species, are susceptible to MAP infection, and strongly support that MAP is the etiologic agent of a subset of patients with Crohn's disease and that it plays a role in the pathogenesis of other human diseases (Naser et al., 2014; Davis, 2015; Kuenstner et al., 2015). Presence of a high bio-load of MAP in domestic and wild ruminants indicates that animals represent a source of MAP infection to humans, directly or indirectly by consumption of animal products (Singh et al., 2014). Infection with MAP is widespread in cattle worldwide and its herd-level prevalence in dairy cattle has been reported to exceed 50\% (Nielsen and Toft, 2009) even in Italy: the apparent prevalence of infected dairy cow herds was reported to range from 19.9 to $65 \%$ with an intraherd prevalence ranging from 2.8 to $5.9 \%$ (Lillini et al., 2005; Pozzato et al., 2011; Marchetti et al., 2013). In Italy, MAP infection was also reported in sheep flocks $(73.7 \%$ of infected herds and 6.29\% of infected animals) and in water buffaloes at lower prevalence (1.2\%; Attili et al., 2011; Gamberale et al., 2014). Dairy cattle represent the largest population of MAP-infected animals and are the most likely source of direct or indirect exposure to humans (NACMCF, 2010) as milk may be contaminated by MAP through direct excretion or by fecal contamination during milking (Grant, 2005). Some investigations have also detected viable MAP in retail pasteurized milk (Grant et al., 2002; Ayele et al., 2005; Ellingson et al., 2005; Shankar et al., 2010; Carvalho et al., 2012); this may be due to postprocess contamination processing or survival through the process. Several thermal inactivation studies on MAP have shown conflicting results, but recent works have demonstrated that thermal processes achieve a 4- to 7-log reduction in the number of MAP cells during industrial-scale experiments (Pearce et al., 2001; Lund et al., 2002; Stabel and Lambertz, 2004; Grant et al., 2005; McDonald et al., 2005; Lynch et al., 
2007; Rademaker et al., 2007). Thus, it appears that regardless of whether MAP is present in pasteurized milk, both the prevalence and the numbers of MAP in pasteurized products will be low (NACMCF, 2010).

Because the public health significance of low numbers of MAP is not known and there are public concerns about human exposure to MAP, we performed a large investigation in 569 Italian farms delivering milk to 3 industrial dairy plants (Marchetti et al., 2013; Serraino et al., 2014a,b). The apparent prevalence in the investigated dairy herds was $6.07 \%$ (range 0.00 to $22.73 \%$; Serraino et al., 2014a). We used the findings to perform a quantitative risk assessment of MAP survival in pasteurized milk, estimating an overall percentage of 0.55 to 0.98 of pasteurized milk bottles having a MAP contamination $>0 \mathrm{cfu} / \mathrm{L}$ and 0.04 to $0.11 \%$ of liters having a contamination $>100 \mathrm{cfu} / \mathrm{L}$ (Serraino et al., 2014b). No data are available on the isolation of MAP in pasteurized milk to validate this estimation, so this study aimed to investigate the presence of viable MAP in pasteurized milk produced by 2 of the 3 Italian industrial dairy plants previously investigated and to verify the prediction of the previously performed risk assessment. The 2 dairy plants were located in 2 different regions and process 38.75 (plant A) and 89.29 (plant B) million liters of milk a year. We analyzed 160 one-liter bottles of pasteurized milk ( 80 bottles for each dairy plant, 10 bottles for 2 consecutive days in 4 samplings throughout the year to have a complete picture of milk consignments). Milk samples were collected in the period from November 2014 to November 2015 directly in the dairy plant at the end of the production line. Samples were transported on ice to the laboratory within $24 \mathrm{~h}$ of collection and analyzed the day after arrival at the laboratory, approximately 48 to $72 \mathrm{~h}$ after production.

Given the expected low contamination level, some changes to traditional cultural protocols were applied to enhance the test's sensitivity: $500 \mathrm{~mL}$ of pasteurized milk for each sample was aliquoted in 10 sterile plastic tubes (each containing $50 \mathrm{~mL}$ ). The tubes were then centrifuged at 2,500 $\times g$ for $15 \mathrm{~min}$ at room temperature $\left(21^{\circ} \mathrm{C}\right)$ and the supernatant was discharged, whereas the remaining pellets were suspended and aggregated in a single tube using PBS for a final volume of $3 \mathrm{~mL}$. The suspensions were then streaked onto 6 Petri plates (diameter $9 \mathrm{~cm}$ ) containing Herrold's egg yolk agar supplemented with mycobactin $\mathrm{J}(2 \mathrm{mg} / \mathrm{L})$, nalidixic acid $(50 \mathrm{mg} / \mathrm{L})$, vancomycin $(50 \mathrm{mg} / \mathrm{L})$, and sodium pyruvate $(4 \mathrm{~g} / \mathrm{L})$. Plates were incubated at $37^{\circ} \mathrm{C}$ for 16 wk and checked monthly for the presence of MAP colonies.

A MAP reference strain (ATCC 19698) was used to determine the limit of detection (LOD) of the method. Mycobacterium avium ssp. paratuberculosis suspensions were prepared according to Logar et al. (2012) and Plain et al. (2014). Briefly, colonies from solid cultures were harvested and suspended in PBS with glass beads (diameter approximately $5 \mathrm{~mm}$ ), then vortexed for 45 $\mathrm{s}$, and the optical density at $600 \mathrm{~nm}$ was adjusted to 0.7 ; the suspensions were forced through a syringe (26$\mathrm{G}$ needle) several times and filtered through a sterile $5-\mu \mathrm{m}$ filter. The suspension was examined in a Bürker chamber to count the number of MAP cells (expressed as MAP cells per $500 \mathrm{~mL}$ of pasteurized milk; see Table 1, "Mean theoretical input" column). The initial suspensions were serially diluted 10-fold in PBS using tubes containing glass beads (diameter approximately $5 \mathrm{~mm}$ ), with vortexing for $20 \mathrm{~s}$ between dilution steps. One hundred microliters of each dilution was streaked in duplicate onto Petri plates (diameter $9 \mathrm{~cm}$ ) of Herrold's egg yolk agar with Mycobactin J (2 mg/L) for the determination of MAP expressed as colony-forming units per $500 \mathrm{~mL}$ of milk.

To determine the LOD, 6 replicates of $500 \mathrm{~mL}$ of pasteurized milk containing concentrations of MAP cells ranging from $8.6 \times 10^{-1}$ to $8.6 \times 10^{1} \mathrm{cfu}$ per $500 \mathrm{~mL}$ of milk (see Table 1, "Mean cultural input" column) were tested by cultural assay. Briefly, $3 \mathrm{~L}$ of milk was spiked with each of the above suspensions of MAP and spiked

Table 1. Limit of detection of the culture method used in the study (American Type Culture Collection 19698 strain)

\begin{tabular}{lccc}
\hline Item & $\begin{array}{c}\text { Mean theoretical input } \\
(\text { MAP cells per 500 mL) }\end{array}$ & $\begin{array}{c}\text { Mean cultural input } \\
(\text { cfu per 500 mL) }\end{array}$ & $\begin{array}{c}\text { Signal }_{\text {ratio }^{3}} \\
\text { Contaminated milk }\end{array} 2^{2.1 \times 10^{2}}$ \\
$2.1 \times 10^{1}$ & $8.6 \times 10^{1}$ & $6 / 6(100 \%)$ \\
Uncontaminated milk & $2.1 \times 10^{0}$ & $8.6 \times 10^{0}$ & $5 / 6(83.3 \%)$ \\
\hline
\end{tabular}

${ }^{1}$ Number of Mycobacterium avium ssp. paratuberculosis (MAP) cells obtained by Bürker chamber count and used to spike $500 \mathrm{~mL}$ of pasteurized milk.

${ }^{2}$ Evaluated by streaking $100 \mu \mathrm{L}$ of each dilution in Herrold's egg yolk agar supplemented with Mycobactin J (2 $\mathrm{mg} / \mathrm{L}$ ) plates in duplicate, reported as cfu per $500 \mathrm{~mL}$ of pasteurized milk.

${ }^{3}$ Number of positive replicates versus total number of replicates obtained with the cultural assay. 
milk was then aliquoted in $50-\mathrm{mL}$ tubes and processed as previously described. Moreover, a negative control in duplicate ( $1 \mathrm{~L}$ of milk) was also processed in parallel with spiked samples. The value of LOD was estimated through logit link function (data from Table 1, column "mean cultural input") as recommended in the OIE Manual of Diagnostic Tests and Vaccines for Terrestrial Animals (OIE-World Organisation for Animal Health, 2012, 2014) using SPSS Statistics 20 (IBM, Armonk, NY).

As some studies have also pointed out the risk of under-pasteurization or postprocess contamination (Lund et al., 2002; Ellingson et al., 2005), we also investigated the pasteurization parameters and industry-generated data on the microbiological characteristics of raw milk (total bacterial count according to EC Regulation 853/2004; EC, 2004) and pasteurized milk (Enterobacteriaceae and Listeria monocytogenes according to EC Regulation 2073/2005; EC, 2005) collected in the 2 plants.

The $\mathrm{LOD}_{95 \%}$ of the method was $11.5 \mathrm{cfu}$ per $500 \mathrm{~mL}$ of milk (ranging from 7.4 to 49.0 cfu per $500 \mathrm{~mL}$ according to logit analysis), corresponding to $0.023 \mathrm{cfu}$ per $\mathrm{mL}$ of milk. Figure 1 and Table 1 show the results of the tests to assess the LOD value of the cultural assay.

None of the 160 samples showed the growth of MAP colonies during the $16 \mathrm{wk}$ of incubation; we observed

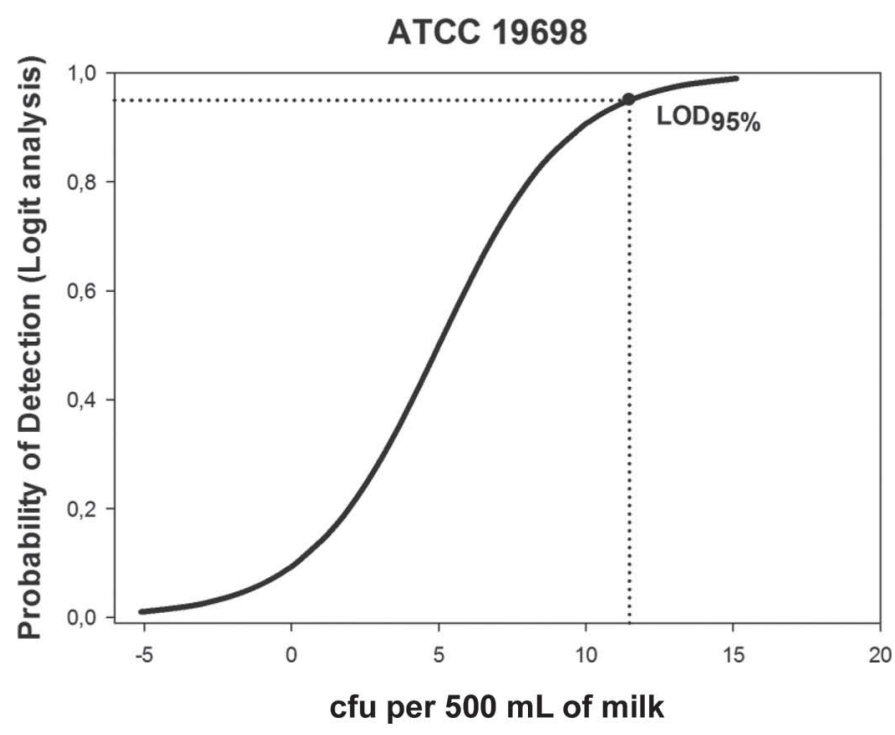

Figure 1. Graph of logit analysis for the determination of the limit of detection (LOD). Dashed lines indicate the $\mathrm{LOD}_{95 \%}$ of Mycobacterium avium ssp. paratuberculosis (strain ATCC 19698) in $500 \mathrm{~mL}$ of milk, estimated as $11.5 \mathrm{cfu}$ per $500 \mathrm{~mL}$ of milk (ranging from 7.4 to 49.0 cfu per $500 \mathrm{~mL}$ of milk; CI were not reported in the graph). an overgrowth of contaminant microflora in 8 out of 160 samples.

The industry collected samples for total bacterial count at every milk load from each farm in plant $\mathrm{A}$ and 8 times a month in plant $\mathrm{B}$; the weighted mean of the bacterial count of all the raw milk collected in plants A and $\mathrm{B}$ was $35,043 / \mathrm{mL}$ and $38,387 / \mathrm{mL}$, respectively. Thermal processing of milk was performed at $76^{\circ} \mathrm{C}$ for $17 \mathrm{~s}$ in plant $\mathrm{A}$ and at $74^{\circ} \mathrm{C}$ for $21 \mathrm{~s}$ in plant $\mathrm{B}$.

A total of 626 and 889 bottles of pasteurized milk and a total of 313 and 339 bulk pasteurized milk samples were analyzed in 2015 for Listeria monocytogenes, Enterobacteriaceae count [analyzed according to Commission Regulation (EC) 2073/2005; EC, 2005], and phosphatase and peroxidase activity in plants $\mathrm{A}$ and $\mathrm{B}$, respectively; results showed the absence of L. monocytogenes in all pasteurized milk samples analyzed, an Enterobacteriaceae count always $<1 \mathrm{cfu} / \mathrm{mL}$, negative phosphatase activity, and positive peroxidase activity.

The lack of MAP positivity in any of the 160 samples appears to contrast with previous investigations that isolated vital MAP in 1.6 to $2.8 \%$ of pasteurized milk samples (Grant et al., 2002; Ayele et al., 2005; Ellingson et al., 2005; Carvalho et al., 2012) up to a very high proportion of positive pasteurized milk samples (67\%) observed in one investigation (Shankar et al., 2010). However, other investigations on pasteurized milk also found no MAP culture (Gao et al., 2002; O'Reilly et al., 2004; Méndez et al., 2006). Several explanations are possible for the different results of investigations into vital MAP in pasteurized milk and experimental tests assessing the efficacy of pasteurization to inactivate MAP in milk (Grant et al., 2002; Cerf et al., 2007). In brief, these differences concern (1) laboratory procedures, (2) postprocessing contamination, (3) underpasteurization conditions, and (4) the number of MAP present in the raw milk before pasteurization.

Among the laboratory procedures, we paid attention to resuscitation and incubation for a sufficient period of time for the recovery of heat-injured MAP cells (Hammer et al., 2004) as the majority of isolates from pasteurized milk are obtained after 8 wk of incubation (Grant, 2004). Moreover, Grant hypothesized that false-negative results may occur in milk tested immediately after pasteurization because sub-lethally heat-injured MAP cells in milk may recover viability if given sufficient time (>48 h; Grant, 2004); longer resuscitation periods did not seem to significantly influence the results (Stabel and Lambertz, 2004).

Chemical decontamination may have a detrimental effect on the viability of MAP. Pearce (2004) reported that decontamination and the use of antibiotics in Herrold's egg yolk medium + mycobactin J do not have a negative effect on the survival of MAP during culturing; 
on the contrary, prolonged exposure to decontaminants influences their survival (Gao et al., 2005). In addition, viable MAP were recovered more frequently from pasteurized milk when antibiotics were omitted or used in reduced quantities (Grant, 2004). Our study tested milk 48 to $72 \mathrm{~h}$ after pasteurization, the incubation was prolonged up to $16 \mathrm{wk}$, and the decontamination step was omitted to enhance the probability of isolating MAP. On the other hand, the addition of antibiotics to the medium was necessary to avoid the overgrowth of contaminant microflora.

Given that low numbers of MAP are likely to survive pasteurization, testing as large a volume of milk as possible should boost the chances of detecting surviving MAP. Grant (2004) reported that viable MAP in pasteurized milk could be isolated only in studies testing at least $50 \mathrm{~mL}$ of milk. Because of the expected low number of MAP predicted, we tested $500 \mathrm{~mL}$ of milk.

Detection of MAP in commercially pasteurized milk does not necessarily indicate that the organism survived pasteurization because under-pasteurization and postprocess contamination may occur (Grant, 2004). Regarding the possibility of under-pasteurization, we accessed processing and self-control data in the dairy plants investigated, finding temperature/time process parameters in line with the normal commercial practice of pasteurizers (usually set at $>73.5$ to $74.0^{\circ} \mathrm{C}$ to provide an additional margin of safety above the legal standard temperature, $71.5^{\circ} \mathrm{C}$; Pearce, 2004). Phosphatase activity and microbiological data on the process hygiene criteria (Enterobacteriaceae; $\mathrm{n}=5, \mathrm{c}=0$, where $\mathrm{c}$ is the number of sample units giving values over the critical limit; limit $10 \mathrm{cfu} / \mathrm{mL})$, together with the absence of $L$. monocytogenes (European Union regulation 2073/2005; EC, 2005), confirmed these data, showing that both dairy plants applied correct pasteurization and appropriate postprocess hygiene procedures.

As the inactivation kinetics of unicellular organisms is a first-order reaction (Cerf et al., 2007), the number of MAP cells present before pasteurization is a key factor for potential survival of MAP after pasteurization (Grant et al., 2002). Sweeney et al. (1992) reported a contamination level from 2 to $8 \mathrm{cfu}$ per $50 \mathrm{~mL}$ of milk for direct excretion in symptomatic or asymptomatic cows, but raw milk can be contaminated with MAP through fecal contamination (Nauta and van der Giessen, 1998) and clinically infected cows can shed up to $10^{12}$ MAP cells per day in feces (Cocito et al., 1994). Studies on the presence of MAP in bulk tank milk showed that milk contamination is mainly related to the presence of clinical and subclinical high shedders (Sweeney et al., 1992; Boulais et al., 2011; Khol et al., 2013) and milking hygiene (Jayarao et al., 2004).
A previous investigation on MAP performed in the same dairy plants detected an apparent mean prevalence of $6.7 \%$ by ELISA in the animals of the farms delivering milk to the plants (Serraino et al., 2014a). This result is similar to the prevalence reported in other studies (Nielsen and Toft, 2009; Carter, 2012). However, we detected a very low proportion $(0.9 \%)$ of MAP-contaminated raw milk samples by quantitative PCR targeting IS900 in comparison with data reported in other surveys reviewed in Okura et al. (2012) and we modeled a 95th percentile of MAP concentration in raw milk of 1.2 to $2.8 \mathrm{cfu} / \mathrm{mL}$ (Serraino et al., 2014b).

Data collected in the 2 dairy plants in the present study showed that plant A measured the total bacterial count of bulk tank milk at each load from each farm (weighted mean of the bacterial count during 2015 was $35,000 / \mathrm{mL}$ ), whereas plant B measured the total bacterial count 8 times a month in each farm (weighted mean of the bacterial count during 2015 was $38,387 / \mathrm{mL}$ ). European legislation (European Union Regulation 853/2004; EC, 2004) defines a maximum level of total bacterial count of $100,000 / \mathrm{mL}$ (geometric mean of 2 mo with at least 2 samples/month). The higher frequency of sampling indicates that the dairy industries put pressure on farmers in terms of raw milk hygiene parameters; the results of total bacterial count monitoring show results fully compliant with European Union legislation, indicating a good level of the milking procedure.

Another aspect to consider is the intensive dairy farming system in Italy, as in other countries: the mean number of lactations per cow reported by the Italian Farmers' Association is 2.4 (Andrighetto, 2011). This suggests that on average cows are culled when they are 4 to $5 \mathrm{yr}$ old, thereby reducing the probability of clinical high shedders. Moreover, dilution during milk collection and other process steps usually applied before pasteurization could also play a role in reducing the MAP load (Hammer et al., 2004).

Mycobacterium avium ssp. paratuberculosis may be cultured from milk after HTST pasteurization if the organism is present in raw milk in sufficient numbers (Millar et al., 1996; Grant et al., 1996, 2002). Okura et al. (2013) reported that a MAP load at a concentration of $10^{4}$ is plausible, but in extreme scenarios that require very poor hygienic conditions. In practice, the likely fecal contamination of raw milk can fluctuate with the level of hygiene during milking, but bulking in the farm or in the dairy company silos or both can dilute MAP spikes and $100 \mathrm{cfu} / \mathrm{mL}$ of MAP contamination at the silo level can be estimated as the worst-case scenario (Pearce et al., 2004). Nauta and van der Giessen (1998) modeled a concentration of $5.4 \mathrm{cfu} / \mathrm{L}$ with the main 
contribution due to clinically affected animals. According to the same model, the exclusion of clinically affected animals from the production chain would reduce the estimated exposure by $99 \%$ to $0.06 \mathrm{cfu} / \mathrm{L}$. Assuming these levels of contamination, a proper pasteurization process should completely kill MAP in milk (Stabel and Lambertz, 2004).

The risk assessment model previously developed (Serraino et al., 2014b) in the dairy plants predicted a proportion of 0.55 to $0.98 \%$ of liters of pasteurized milk having a MAP contamination $>0 \mathrm{cfu} / \mathrm{L}$ considering a max 7-log reduction (range 4- to 7-log reduction) of MAP concentration due to pasteurization. Assuming a binomial distribution for positive/negative probability of detecting MAP-positive pasteurized milk and 95\% sensitivity at LOD level of the applied method, the results of the present study (no positive milk out of 160 samples) indicate a maximal prevalence of about $1.3 \%$ of milk (95\% confidence level) in line with the predicted estimation of the model. As noted by Hammer et al. (2006) and reported by the National Advisory Committee on Microbiological Criteria for Foods (NACMCF, 2010), "despite all uncertainties regarding complete inactivation of (MAP) during heat treatment and possible reasons for survival, a reduction of at least 5 to $7 \log 10$ cycles could be demonstrated in whole milk, skim milk and cream. In the framework of the Codex Alimentarius for samples of pasteurized milk, this should be fully sufficient."

In conclusion, our results show that a $7-\log$ ( or $>7$ ) reduction could be a plausible value for commercial milk pasteurization and that the combination of current hygienic farm practices and commercial pasteurization results in very low or absent levels of MAP contamination in pasteurized milk, suggesting that pasteurized milk is not a significant source of human exposure to MAP in the investigated dairies.

\section{REFERENCES}

Andrighetto, I. 2011. La vacca da latte oggi tra produzione e riproduzione. Informatore agrario, 18:76-87. Accessed May 18, 2016. http://www.informatorezootecnico.it/agri24/pdf/ IZ_11_18_bovino_latte.pdf.

Attili, A. R. V. Ngu Ngwa, S. Preziuso, L. Pacifici, A. Domesi, and V. Cuteri. 2011. Ovine paratuberculosis: A seroprevalence study in dairy flocks reared in the Marche region, Italy. Vet. Med. Int. 11:782875. https://doi.org/10.4061/2011/782875.

Ayele, W. Y., P. Svastova, P. Roubal, M. Bartos, and I. Pavlik. 2005. Mycobacterium avium subspecies paratuberculosis cultured from locally and commercially pasteurized cow's milk in the Czech Republic. Appl. Environ. Microbiol. 71:1210-1214.

Boulais, C., R. Wacker, J. C. Augustin, M. H. B. Cheikh, and F. Peladan. 2011. Modelling the occurrence of Mycobacterium avium ssp. paratuberculosis in bulk raw milk and the impact of management options for exposure mitigation. J. Food Prot. 74:1126-1136.

Carter, M. A. 2012. Prevalence and prevention of paratuberculosis in North America. Jpn. J. Vet. Res. 60:S9-S18.
Carvalho, I. A., P. A. G. Pietralonga, D. G. G. Schwarz, A. C. S. Faria, and M. A. S. Moreira. 2012. Short communication: Recovery of viable Mycobacterium avium subspecies paratuberculosis from retail pasteurized whole milk in Brazil. J. Dairy Sci. 95:6946-6948.

Cerf, O., M. Griffiths, and F. Aziza. 2007. Assessment of the prevalence of Mycobacterium avium ssp. paratuberculosis in commercially pasteurized milk. Foodborne Pathog. Dis. 4:433-447.

Chiodini, R. J., W. M. Chamberlin, J. Sarosiek, and R. W. McCallum. 2012. Crohn's disease and the mycobacterioses: A quarter century later. Causation or simple association? Crit. Rev. Microbiol. 38:52-93.

Cocito, C., P. Gilot, M. Coene, M. Dakesel, P. Poupart, and P. Vannuffel. 1994. Paratuberculosis. Clin. Microbiol. Rev. 7:328-345.

Davis, W. C. 2015. On deaf ears, Mycobacterium avium paratuberculosis in pathogenesis Crohn's and other diseases. World J. Gastroenterol. 21:13411-13417.

EC (European Commission). 2004. Commission Regulation (EC) No. 853/2004 of the European Parliament and of the Council of 29 April 2004 laying down specific hygiene rules for on the hygiene of foodstuffs. Official Journal of the European Union, 30/4/2004.

EC (European Commission). 2005. Commission Regulation (EC) No. $2073 / 2005$ of 15 November 2005 on microbiological criteria for foodstuffs. Official Journal of the European Union, 22/12/2005.

Ellingson, J. L. E., J. J. Koziczkowski, and J. L. Anderson. 2005 Detection of viable Mycobacterium avium ssp. paratuberculosis in retail pasteurized whole milk by two culture methods and PCR. J. Food Prot. 68:966-972.

Gamberale, F., G. Barlozzari, G. De Santis, P. Scaramella, G. Pietrella, M. Sala, and G. Macrì. 2014. Paratuberculosis in Italian Mediterranean buffalo: Serological screening and prevalence study in a breeding farm in the province of Rome. 12th ICP Congress. Parma June 22-26, 2014.

Gao, A., L. Mutharia, S. Chen, K. Rahn, and J. Odumeru. 2002. Effect of pasteurization on survival of Mycobacterium paratuberculosis in milk. J. Dairy Sci. 85:3198-3205.

Gao, A., J. Odeumeru, M. Raymond, and L. Mutharia. 2005. Development of improved method for isolation of Mycobacterium avium subsp. paratuberculosis from bulk tank milk: Effect of age of milk, centrifugation, and decontamination. Can. J. Vet. Res. 69:81-87.

Grant, I. R. 2004. Inactivation of Mycobacterium avium ssp. Paratuberculosis in milk during commercial HTST pasteurization. Pages 62-68 in Bulletin of the IDF No. 392/2004, Food Safety Objective (FSO) \& Performance Objective (PO), Heat Resistance of Pathogenic Organisms.

Grant, I. R. 2005. Zoonotic potential of Mycobacterium avium ssp. paratuberculosis: The current position. J. Appl. Microbiol. 98:1282-1293.

Grant, I. R., H. J. Ball, S. D. Neill, and M. T. Rowe. 1996. Inactivation of Mycobacterium paratuberculosis in cow's milk at pasteurization temperatures. Appl. Environ. Microbiol. 62:631-636.

Grant, I. R., H. J. Ball, and M. T. Rowe. 2002. Incidence of Mycobacterium paratuberculosis in bulk raw and commercially pasteurized cow's milk from approved dairy processing establishments in the United Kingdom. Appl. Environ. Microbiol. 68:2428-2435.

Grant, I. R., A. G. Williams, M. T. Rowe, and D. D. Muir. 2005. Efficacy of various pasteurization time-temperature conditions in combination with homogenization on inactivation of Mycobacterium avium ssp. paratuberculosis in milk. Appl. Environ. Microbiol. 71:2853-2861.

Hammer, P., C. Kiesner, H. G. Walte, and P. Teufel. 2006. Inactivation of Mycobacterium avium ssp. paratuberculosis in whole milk, skim milk and cream in a pilot plant pasteurizer. Kiel. Milchwirstch. Forschunbsber. 58:17-40.

Hammer, P., C. Kisner, H. G. Walte, K. Knappstein, and P. Teufel. 2004. Heat resistance of Mycobacterium avium ssp. paratuberculosis-in raw milk tested in a pilot-plant pasteurizer. Pages 53-60 in Bulletin of the IDF No. 392/2004, Food Safety Objective (FSO) \& Performance Objective (PO), Heat Resistance of Pathogenic Organisms.

Jayarao, B. M., S. R. Pillai, D. R. Wolfgang, D. R. Griswold, C. A. Rossiter, D. Tewari, C. M. Burns, and L. J. Hutchinson. 2004. 
Evaluation of IS900 assay for detection of Mycobacterium avium subspecies paratuberculosis infection in cattle using quarter milk and bulk tank milk samples. Foodborne Pathog. Dis. 1:17-26.

Khol, J. L., M. Wassertheurer, E. Sodoma, S. Revilla-Fernández, J. Damoser, E. Österreicher, M. Dünser, U. Kleb, and W. Baumgartner. 2013. Long-term detection of Mycobacterium avium subspecies paratuberculosis in individual and bulk tank milk from a dairy herd with a low prevalence of Johne's disease. J. Dairy Sci. 96:35173524 .

Kuenstner, J. T., W. Chamberlin, S. A. Naser, M. T. Collins, C. T. Dow, J. M. Aitken, S. Weg, G. Telega, K. John, D. Haas, T. M. Eckstein, M. Kali, C. Welch, and T. Petrie. 2015. Resolution of Crohn's disease and complex regional pain syndrome following treatment of paratuberculosis. World J. Gastroenterol. 21:4048 4062.

Lillini, E., G. Bitonti, F. Gamberale, and A. Cersini. 2005. Prevalence of bovine paratuberculosis in the Latium region (Italy). Accessed Jun. 7, 2016. http://www.paratuberculosis.info/web/images/ stories/pdfs/197.

Logar, K., R. Kopinč, P. Bandelj, J. Starič, A. Lapanje, and M. Ocepek. 2012. Evaluation of combined high-efficiency DNA extraction and real-time PCR for detection of Mycobacterium avium ssp. paratuberculosis in subclinically infected dairy cattle: comparison with faecal culture, milk real-time PCR and milk ELISA. BMC Vet. Res. 8:49.

Lund, B. M., G. W. Gould, and A. M. Rampling. 2002. Pasteurization of milk and the heat resistance of Mycobacterium avium ssp. paratuberculosis: A critical review of the data. Int. J. Food Microbiol. $77: 135-145$

Lynch, D., K. N. Jordan, P. M. Kelly, T. Freyne, and M. M. Murphy. 2007. Heat sensitivity of Mycobacterium avium ssp. paratuberculosis in milk under pilot plant pasteurization conditions. Int. J. Dairy Technol. 60:98-104.

Marchetti, G., M. Ricchi, A. Serraino, F. Giacometti, E. Bonfante, and N. Arrigoni. 2013. Prevalence of Mycobacterium avium ssp. paratuberculosis in milk and dairy cattle in Southern Italy; preliminary results. Ital. J. Food Saf. 35:124-127.

McDonald, W. L., K. J. O'Riley, C. J. Schroen, and R. J. Condron. 2005. Heat inactivation of Mycobacterium avium ssp. paratuberculosis in milk. Appl. Environ. Microbiol. 71:1785-1789.

Méndez, D., F. Gimenéz, A. Escalona, O. Da Mata, A. Gonzàles, H. Takiff, and J. H. de Waard. 2006. Mycobacterium bovis cultured from commercially pasteurized cow's milk: Laboratory cross-contamination. Vet. Microbiol. 116:325-328.

Millar, D., J. Ford, J. Sanderson, S. Withey, M. Tizard, T. Doran, and T. J. Hermon. 1996. IS900 PCR to detect Mycobacterium paratuberculosis in retail supplies of whole pasteurized cow's milk in England and Wales. Appl. Environ. Microbiol. 62:3446-3452.

NACMCF (National Advisory Committee on Microbiological Criteria for Foods). 2010. Assessment of food as a source of exposure to Mycobacterium avium subspecies paratuberculosis (MAP). J. Food Prot. 73:1357-1397.

Naser, S. A., S. R. Sagramsingh, A. S. Naser, and S. Thanigachalam. 2014. Mycobacterium avium subspecies paratuberculosis causes Crohn's disease in some inflammatory bowel disease patients. World J. Gastroenterol. 20:7403-7415.

Nauta, M. J., and J. W. B. van der Giessen. 1998. Human exposure to Mycobacterium paratuberculosis via pasteurized milk: A modeling approach. Vet. Rec. 143:293-296.

Nielsen, S. S., and N. Toft. 2009. A review of prevalence of paratuberculosis in farmed animals in Europe. Prev. Vet. Med. 88:1-14.

OIE-World Organisation for Animal Health. 2012. Principles and methods of validation of diagnostic assays for infectious diseases (version adopted in May, 2013). Pages 1-16 in Terrestrial Manual. 7th ed. OIE-World Organisation for Animal Health, Paris, France.

OIE-World Organisation for Animal Health. 2014. OIE Validation Guidelines 2014. Pages 1-12 Validation Guideline 3.6.5. Statistical Approaches To Validation. OIE-World Organisation for Animal Health, Paris, France.
Okura, H., S. S. Nielsen, and N. Tolf. 2013. Modeling the effect of direct and indirect contamination of on-farm bulk tank milk with Mycobacterium avium ssp. paratuberculosis. Foodborne Pathog. Dis. 10:270-277.

Okura, H., N. Tolf, and S. S. Nielsen. 2012. Occurrence of Mycobacterium avium ssp. paratuberculosis in milk at dairy cattle farms: A systematic review and meta-analysis. Vet. Microbiol. 157:253-263.

O'Reilly, C. E., L. O'Connor, W. Anderson, P. Harvey, I. R. Grant, J. Donaghy, M. Rowe, and P. O'Mahony. 2004. Surveillance of bulk raw and commercially pasteurized cows' milk from approved Irish liquid-milk pasteurization plants to determine the incidence of Mycobacterium paratuberculosis. Appl. Environ. Microbiol. 70:5138-5144.

Pearce, L. E. 2004. Survey of data on heat resistance of dairy pathogens. Pages 37-41 in Bulletin of the IDF No. 392/2004-Food Safety Objective (FSO) \& Performance Objective (PO) - Heat Resistance of Pathogenic Organisms.

Pearce, L. E., H. T. Truong, R. A. Crawford, and G. W. de Lisle. 2004 Kinetic studies on the heat inactivation of Mycobacterium avium ssp. paratuberculosis-(MAP) during turbulent-flow pasteurization. Pages 49-52 in Bulletin of the IDF No. 392/2004, Food Safety Objective (FSO) \& Performance Objective (PO), Heat Resistance of Pathogenic Organisms.

Pearce, L. E., H. T. Truong, R. A. Crawford, G. F. Yates, S. Cavaignac, and G. W. de Lisle. 2001. Effect of turbulent-flow pasteurization on survival of Mycobacterium avium ssp. paratuberculosis added to raw milk. Appl. Environ. Microbiol. 67:3964-3969.

Plain, K. M., I. B. Marsh, A. M. Waldron, F. Galea, A. M. Whittington, V. F. Saunders, D. J. Begg, K. de Silva, A. C. Purdie, and R. J. Whittington. 2014. High-throughput direct fecal PCR assay for detection of Mycobacterium avium ssp. paratuberculosis in sheep and cattle. J. Clin. Microbiol. 52:745-757.

Pozzato, N., K. Capello, A. Comin, N. Toft, S. S. Nielsen, G. Vicenzoni, and N. Arrigoni. 2011. Prevalence of paratuberculosis infection in dairy cattle in Northern Italy. Prev. Vet. Med. 102:83-86.

Rademaker, J. L. W., M. M. M. Vissers, and M. C. te Giffel. 2007. Effective heat inactivation of Mycobacterium avium ssp. paratuberculosis in raw milk contaminated with naturally infected feces. Appl. Environ. Microbiol. 73:4185-4190.

Serraino, A., N. Arrigoni, F. Ostanello, M. Ricchi, G. Marchetti, P. Bonilauri, E. Bonfante, and F. Giacometti. 2014a. A screening sampling plan to detect Mycobacterium avium ssp. paratuberculosis-positive dairy herds. J. Dairy Sci. 97:3344-3351.

Serraino, A., P. Bonilauri, N. Arrigoni, F. Ostanello, M. Ricchi, G. Marchetti, E. Bonfante, S. Albonetti, and F. Giacometti. 2014b. Quantitative risk assessment of Mycobacterium avium ssp. paratuberculosis survival in pasteurized milk in three dairy plants in Italy. Food Contr. 45:120-126.

Shankar, H., S. V. Singh, P. K. Singh, A. V. Singh, J. S. Sohal, and R. J. Greenstein. 2010. Presence, characterization, and genotype profiles of Mycobacterium avium subspecies paratuberculosis from unpasteurized individual and pooled milk, commercial pasteurized milk, and milk products in India by culture, PCR, and PCE-REA methods. Int. J. Infect. Dis. 14:e121-e126.

Singh, S. V., N. Kumar, J. S. Sohal, A. V. Singh, P. K. Singh, N. D. Agrawal, S. Gupta, K. K. Chaubey, R. Deb, R. Dhama, and R. Rawat. 2014. First mass screening of the human population to estimate the bio-load of Mycobacterium avium sub-species paratuberculosis in North India. JPHE 6:20-29.

Stabel, J. R., and A. Lambertz. 2004. Efficacy of pasteurization conditions for the inactivation of Mycobacterium avium ssp. paratuberculosis in milk. J. Food Prot. 67:2719-2726.

Sweeney, R. W., R. H. Whitlock, and A. E. Rosemberger. 1992. Mycobacterium paratuberculosis cultured from milk and supramammary lymph nodes of infected asymptomatic cows. J. Clin. Microbiol. $30: 166-171$. 